\title{
Preliminary Study of Differences Between Prevalence of Multiple Sclerosis in Isfahan and its' Rural Provinces
}

\author{
Zahra Tolou-Ghamari, ${ }^{1 *}$ \\ ${ }^{1}$ Isfahan Neurosciences Research Centre, Faculty of Medicine, Isfahan University of Medical Sciences, Isfahan, IR Iran \\ ${ }^{*}$ Corresponding author:Zahra Tolou-Ghamari, Isfahan Neurosciences Research Centre, Faculty of Medicine, Isfahan University of Medical Sciences, Isfahan, IR Iran. Tel: +98-3136291050, \\ Fax:+98-3136680011, E-mail: toloeghamari@pharm.mui.ac.ir
}

Received: April 5, 2015; Accepted: May 9, 2015

\begin{abstract}
Background: Previous publications categorized Isfahan as a high-risk area with regard to the prevalence and incidence of multiple sclerosis(MS).

Objectives: Till to date, there have been no studies differentiating between the prevalence of MS in Isfahan and its rural provinces.

Patients and Methods: A retrospective study of 4,209 patients with MS was conducted and recorded by the deputy of health at the Isfahan university of medical sciences in 2013. Demographic variables and place of birth were recorded in Excel. Descriptive and comparative analyses were conducted using SPSS.

Results: For Isfahan and its rural provinces, the calculated prevalence of MS could be referred as $\mathrm{P}=84.14$. The calculated prevalence of MS for Isfahan was as $\mathrm{P}=27.61$. It seems that the highest MS populations are located in the Isfahan rural southwest provinces. The place of birth in $52 \%$ was Isfahan. The number of women (78\%) was higher than that of men (22\%), and $90 \%$ of the population was young (range: 20 - 50 years old).

Conclusions: The outcome of this preliminary study suggested that Isfahan and its rural provinces might be categorized as two distinct regions for epidemiology of MS. Medium-risk areas included Isfahan, and high-risk areas included the Isfahan rural southwest provinces. Further advanced studies in this direction are recommended.
\end{abstract}

Keywords: Birthplace; Regions; Prevalence; Multiple Sclerosis

\section{Background}

Traditionally, the current dilemma regarding early justification of the clinical and pathological manifestation of Hirnsklerose, also known as brain sclerosis or multiple sclerosis (MS), began in 1849 with Friedrich von Frerichs (1).

MS is a recurrent neurological disease with growing incidence and prevalence worldwide and in the Middle East (2-5).

There are many possibilities for the cause of MS. A recent publication confirms that it could be caused by viral disease with intestinal pathology and relevance to smoked and nitrate/nitrite-cured meat products in the diet throughout restricted time periods (6).

European studies of its incidence and prevalence have shown marked geographical disparities in available data (7). A higher proportion of women among MS patients $(\mathrm{M}: \mathrm{F}=1: 2.61$ ), longer disease period (mean $14.3 \pm 10.6$ years, maximum 53 years), and greater life expectancy $(44.3 \pm 12.7$ years, maximum 77 years $)$ was reported for the Northwest administrative district of Moscow in 2008 - 2012 (8). For Hungary, an increased prevalence of MS was reported, placing it as a medium-risk country (9). A crude prevalence of 203 was reported for Norway (10).

A relative risk of MS was reported as 3.39 female:male and 1.27 black:white, obtained from 2,691 patients from the US military-veteran population (11). People with darker skins a have lower vitamin D levels and might be more susceptible to an increased risk of MS. It seems that factors influencing vitamin D levels may differ in patients with MS. Study of 149 Arabic MS patients (78 Muslims, 49 Christians, and 22 Druze) showed that Druze and Muslims exhibited a more rapid disease course in comparison with Christians (12-14).

The epidemiology of MS has altered in recent decades in the Middle East (2-5). Prevalence of $\mathrm{P}=31$ - 55, $\mathrm{P}=85.05$, and $\mathrm{P}=54.4$ has been reported for Persian Gulf countries, Kuwait, and the United Arab Emirates, respectively. Within Iran, the highest and lowest prevalence was reported in Isfahan $(\mathrm{P}=93.06)$ and Golestan $(P=18.0)$, respectively (2). Study of demographic characteristics of MS in two ethnic groups, Persian and Arabic, showed that incidence and prevalence were higher in Persians (15). 
The incidence and prevalence of MS in Isfahan has been increasing rapidly, especially in women (16).

\section{Objectives}

This study aimed to differentiate between the prevalence of MS in Isfahan and the Isfahan rural provinces.

\section{Patients and Methods}

This was a retrospective descriptive study of all MS patients recorded up to 2013 by the deputy of health at the Isfahan University of Medical Sciences. A total of 4,209 patients with MS were involved. The Isfahan and Isfahan rural province populations were based on government census. The criteria used to diagnose MS were based on clinical, imaging, or other laboratory studies or all of these combined. In this preliminary study, all kinds of MS patients were examined. No attempt was made at this stage to classify patients into the categories of relapsing/remitting and chronic progressive. Because there was no intervention regarding treatment management, there was no need for consent. All patients were alive, and there were no exclusion criteria. Demographic, clinical, and pharmacological variables for each patient were recorded in d-Base. The size of the at-risk population and the number of patients with MS were recorded in d-Base and analyzed in Excel. Prevalence was calculated as the proportion of the MS population divided by the number of people in the population. Descriptive and comparative analyses were conducted using the statistical package for the social sciences (SPSS) version 13.

(1) Prevalence $=\frac{\text { Proportion of the MS population during aspecified time period }}{\text { population during the same time period }} \times 100$

\section{Results}

There were 3,279 women (78\%) and 930 (22\%) men. The ratio of women to men was 3.55. Figure 1 shows the distribution of age within the population studied. In $90 \%$ of patients, age ranged from 20 to 50 years. Analysis of patients according to place of birth showed that 56\% of patients with MS were born in Isfahan. The place of birth for $28 \%$ was the Isfahan rural provinces. In $16 \%$, the places of birth were other cities of Iran. The calculated prevalence $(\mathrm{P})$ for Isfahan could be presented as $P=84.14$. Figure 2 shows that, according to place of birth, prevalence for Isfahan could be referred to as $\mathrm{P}$ $=27.61$. Additionally, prevalence for the Isfahan rural provinces was as follows: Mobarakeh $\mathrm{P}=131.3$, Falavarjan $P=67.66$, Semirom $P=55.9$, Najafabad $P=30.43$, and Lenjan $\mathrm{P}=26.58$. Preliminary analysis related to disease-modifying drugs showed that the most widely prescribed immunomodulating drugs were as follows: cinnoVex $(n=1650)$, betaferon $(n=814)$, rebif $(n=645)$, avonnex $(n=389)$, recigen $(n=210)$, ziferone $(n=130)$, actovex $(n=129)$, actoferon $(n=47)$, actorif $(n=15)$, and extavia $(n=55)$.

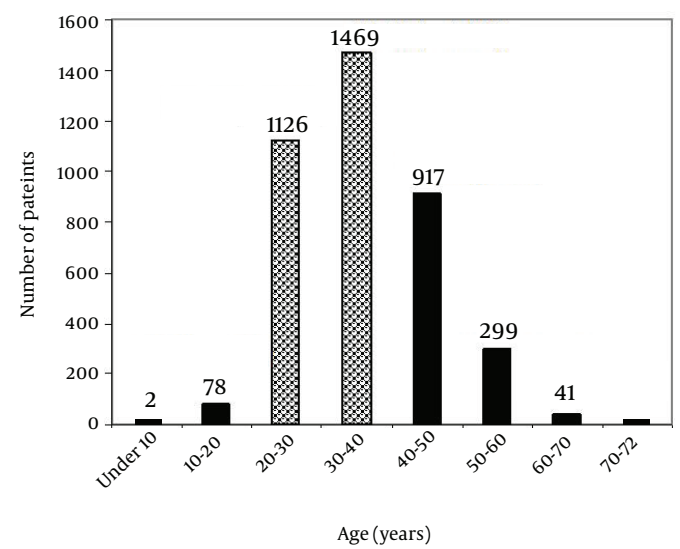

Figure 1. Distribution of Age in Population Studied

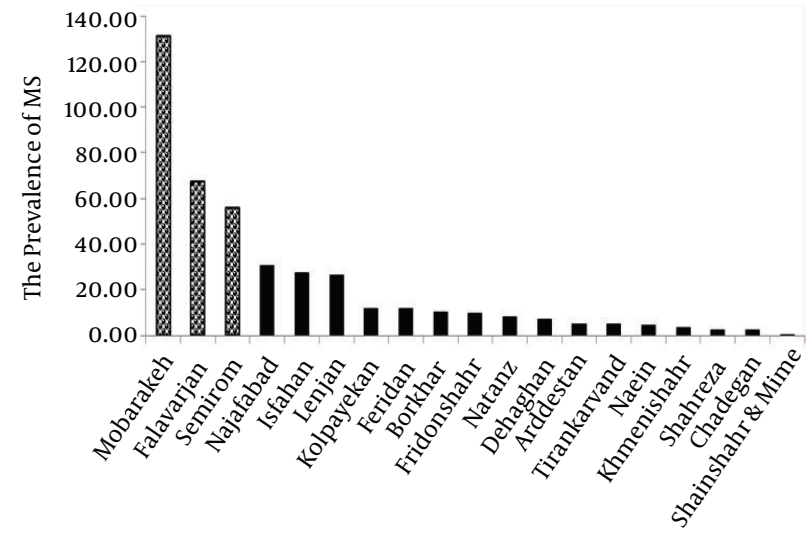

Figure 2. The Prevalence of MS in Isfahan and the Isfahan Rural Provinces

\section{Discussion}

In agreement with a recent publication, the results of this investigation also verified that MS is at least 3.55 times more common in women than in men, suggesting that hormones may also play a significant role in determining susceptibility to MS. Most patients (90\%) are diagnosed between the ages of 20 and 50 years, although MS can occur in young children and older adults. Previous 
publications reported that Isfahan could be considered as an area with a medium to high risk of MS, especially in the young female population (17-20).

Regarding a possible immigration effect, the sex ratio increased in immigrants to Canada and was variable by region of origin and influenced by age at migration (21). A study in Sweden related to Iranian immigrants showed a greater prevalence of MS (22). In this study, analysis of patients related to place of birth showed that $16 \%$ were immigrants, and the place of birth was not Isfahan or the Isfahan rural provinces.

Regarding latitude, it seems that MS was reported with much greater frequency above the $40^{\circ}$ latitude than closer to the equator; As the latitude of Isfahan is about 32.65 $\mathrm{N}$ and $51.65 \mathrm{E}$, many publications reported the risk of MS and the effects of solar ultraviolet radiation contact over vitamin D-related protected variation $(23,24)$.

Infectious mononucleosis may point toward a correlation with solar radiation or other factors with a similar latitudinal and seasonal variation. Linked to air pollution, the presence of industrial factories located in the Isfahan rural provinces of Iran could be another explanation and confirms a need for future investigation in this direction. Another justification might be associated with Zayanderud, where $80 \%$ of the extracted water is used for agriculture, especially its popular rice called Lenjan Rice.

Presence of different industries, charisma of nitrophenol compounds in meat following nitrite curing and smoking, history of elevated exposure to organic solvents, cosmetic colors, migration, and electrical power installers have been reported previously (25-31).

Advanced studies are recommended to differentiate the cause for high prevalence of MS in Isfahan, Iran.

\section{Acknowledgements}

The author would like to expresses special thanks to the Isfahan university of medical sciences.

\section{References}

1. Ganesh A, Stahnisch FW. A history of multiple sclerosis investigations in Canada between 1850 and 1950. Can J Neurol Sci. 2014;41(3):320-32.

2. Tolou-Ghamari Z. A Review of Geoepidemiological Differences of Multiple Sclerosis in Iran and Other Middle East Countries. Arch Neurosci. 2014;2(3):e22028.

3. Al Tahan AM, Alsharoqi I, Bohlega SA, Dahdaleh M, Daif A, Deleu D, et al. Characteristics of multiple sclerosis in the Middle East with special reference to the applicability of international guidelines to the region. Int J Neurosci. 2014;124(9):635-41.

4. Benamer HT, Ahmed ES, Al-Din AS, Grosset DG. Frequency and clinical patterns of multiple sclerosis in Arab countries: a systematic review. J Neurol Sci. 2009;278(1-2):1-4.

5. Akhtar N, Elsetouhy A, Deleu D, Kamran S, AlHail H, Elalamy O, et al. Newly diagnosed multiple sclerosis in state of Qatar. Clin Neurol Neurosurg. 2013;115(8):1333-7.

6. Lauer K. Notes on the epidemiology of multiple sclerosis, with special reference to dietary habits. Int J Mol Sci. 2014;15(3):3533-45.

7. Kingwell E, Marriott JJ, Jette N, Pringsheim T, Makhani N, Morrow $\mathrm{SA}$, et al. Incidence and prevalence of multiple sclerosis in Europe: a systematic review. BMC Neurol. 2013;13:128.
8. Boiko AN, Kukel TM, Lysenko MA, Vdovichenko TV, Gusev EI. Clinical epidemiology of multiple sclerosis in Moscow. capital ES, Cyrilliclinical demo-graphic characteristics in population of one region of Moscow [in Russian]. Zh Nevrol Psikhiatr Im S S Korsakova. 2014;114(2 Vypusk 2 Rasseiannyi skleroz):10-5.

9. Zsiros V, Fricska-Nagy Z, Fuvesi J, Kincses ZT, Langane E, Paulik E, et al. Prevalence of multiple sclerosis in Csongrad County, Hungary. Acta Neurol Scand. 2014;130(5):277-82.

10. Harbo HF, Isobe N, Berg-Hansen P, Bos SD, Caillier SJ, Gustavsen MW, et al. Oligoclonal bands and age at onset correlate with genetic risk score in multiple sclerosis. Mult Scler. 2014;20(6):660-8.

11. Wallin MT, Culpepper WJ, Coffman P, Pulaski S, Maloni H, Mahan CM, et al. The Gulf War era multiple sclerosis cohort: age and incidence rates by race, sex and service. Brain. 2012;135(Pt 6):1778-85

12. Langer-Gould A, Brara SM, Beaber BE, Zhang JL. Incidence of multiple sclerosis in multiple racial and ethnic groups. Neurology. 2013;80(19):1734-9.

13. Amezcua L, Chung RH, Conti DV, Langer-Gould AM. Vitamin D levels in Hispanics with multiple sclerosis. $J$ Neurol. 2012;259(12):2565-70.

14. Siegel M, Paperna T, Lejbkowicz I, Petrou P, Shahien R, Karussis D, et al. Multiple sclerosis in diverse populations: characteristics in distinct Arab ethnicities in Israel. Mult Scler. 2012;18(12):1737-44.

15. Sharafaddinzadeh N, Moghtaderi A, Majdinasab N, Dahmardeh M, Kashipazha D, Shalbafan B. The influence of ethnicity on the characteristics of multiple sclerosis: a local population study between Persians and Arabs. Clin Neurol Neurosurg. 2013;115(8):1271-5.

16. Etemadifar M, Sajjadi S, Nasr Z, Firoozeei TS, Abtahi SH, Akbari M, et al. Epidemiology of multiple sclerosis in Iran: a systematic review. Eur Neurol. 2013;70(5-6):356-63.

17. Harbo HF, Gold R, Tintore M. Sex and gender issues in multiple sclerosis. Ther Adv Neurol Disord. 2013;6(4):237-48.

18. McLeod JG, Hammond SR, Kurtzke JF. Migration and multiple sclerosis in United Kingdom and Ireland immigrants to Australia: a reassessment. II. Characteristics of early (pre-1947) compared to later migrants. J Neurol. 2012;259(4):684-93.

19. Tolou-Ghamari Z, Shaygannejad V, Ashtari F. Preliminary study related the incidence of methylprednisolone pulse therapy in patients visited multiple sclerosis clinic located at the isfahan kashani hospital. Int J Prev Med. 2013;4(Suppl 2):S274-8.

20. Orton SM, Ramagopalan SV, Brocklebank D, Herrera BM, Dyment DA, Yee IM, et al. Effect of immigration on multiple sclerosis sex ratio in Canada: the Canadian Collaborative Study. J Neurol Neurosurg Psychiatry. 2010;81(1):31-6.

21. Guimond C, Dyment DA, Ramagopalan SV, Giovannoni G, Criscuoli M, Yee IM, et al. Prevalence of MS in Iranian immigrants to British Columbia, Canada. J Neurol. 2010;257(4):667-8.

22. van Leeuwen MT, Turner JJ, Falster MO, Meagher NS, Joske DJ, Grulich AE, et al. Latitude gradients for lymphoid neoplasm subtypes in Australia support an association with ultraviolet radiation exposure. Int J Cancer. 2013;133(4):944-51.

23. Hart PH, Gorman S. Exposure to UV Wavelengths in Sunlight Suppresses Immunity. To What Extent is UV-induced Vitamin D3 the Mediator Responsible? Clin Biochem Rev. 2013;34(1):3-13.

24. Lossius A, Riise T, Pugliatti M, Bjornevik K, Casetta I, Drulovic J, et al. Season of infectious mononucleosis and risk of multiple sclerosis at different latitudes; the EnvIMS Study. Mult Scler. 2014;20(6):669-74.

25. Robinson C, Stern F, Halperin W, Venable H, Petersen M, Frazier T, et al. Assessment of mortality in the construction industry in the United States, 1984-1986. Am J Ind Med. 1995;28(1):49-70.

26. Lauer K. Risk of multiple sclerosis in relation to industrial activities: an ecological study in four European countries. Neuroepidemiology. 1989;8(1):38-42.

27. Riise T, Moen BE, Kyvik KR. Organic solvents and the risk of multiple sclerosis. Epidemiology. 2002;13(6):718-20.

28. Landtblom AM, Flodin U, Karlsson M, Palhagen S, Axelson O, Soderfeldt B. Multiple sclerosis and exposure to solvents, ionizing radiation and animals. Scand J Work Environ Health. 


\section{Tolou-Ghamari Z}

1993;19(6):399-404

29. Gronning M, Albrektsen G, Kvale G, Moen B, Aarli JA, Nyland H. Organic solvents and multiple sclerosis: a case-control study. Acta Neurol Scand.1993;88(4):247-50.

30. Lauer K. Environmental associations with the risk of multiple sclerosis: the contribution of ecological studies. Acta Neurol Scand Suppl.1995;161:77-88.

31. Stein EC, Schiffer RB, Hall WJ, Young N. Multiple sclerosis and the workplace: report of an industry-based cluster. Neurology. 1987;37(10):1672-7. 